\title{
In Vitro Effects of Cooking Methods on Digestibility of Lipids and Formation of Cholesterol Oxidation Products in Pork
}

\author{
Sun Jin Hur, Seung Yuan Lee, Sung Sil Moon ${ }^{1}$, and Seung Jae Lee* \\ Department of Animal Science and Technology, Chung-Ang University, Anseong 456-756, Korea \\ ${ }^{1}$ Sunjin Meat Research Center, Seoul 134-060, Korea
}

\begin{abstract}
This study investigated the effects of cooking methods on the digestibility of lipids and formation of cholesterol oxidation products (COPs) in pork, during in vitro human digestion. Pork patties were cooked using four different methods (oven cooking, pan frying, boiling, and microwaving), to an internal temperature of approximately $85^{\circ} \mathrm{C}$. The digestibility of pork patties were then evaluated, using the in vitro human digestion model that simulated the composition ( $\mathrm{pH}$, minerals, surfaceactive components, and enzymes) of digestive juices in the human mouth, stomach, and small intestine. The total lipid digestibility was higher after microwave cooking, whereas pan-frying resulted in lower in vitro digestibility, compared to the other cooking methods. The microwaving method followed by in vitro digestion also showed significantly higher content of free fatty acids and thiobarbituric acid reactive substances (TBARS), compared to the other cooking methods; whereas, the pan frying and boiling methods showed the lowest. Cholesterol content was not significantly different among the cooked samples before, and after in vitro human digestion. The formation of COPs was significantly higher in the microwave-treated pork samples, compared to those cooked by the other methods, which was consistent with the trend for lipid peroxidation (TBARS). We propose that from the point of view of COPs formation and lipid oxidation, the pan-frying or boiling methods would be useful.
\end{abstract}

Keywords: cooking methods, in vitro human digestion, lipid digestibility, lipid oxidation, cholesterol oxidation products

\section{Introduction}

Lipid oxidation occurring in meat during cooking is the process behind the production of volatile substances that account for taste and odor of the cooked food (Broncano et al., 2009). However, excessive lipid peroxidation during cooking process can also lead to a loss of meat nutritional value mainly due to formation of cholesterol oxidation products (COPs) (Hur et al., 2007). It is known that changes in food quality during cooking correlate with temperature and cooking times (Broncano et al., 2009) and that extended exposure to high temperatures can generate highly oxidized products, which can negatively affect food quality (Kesava Rao et al., 1996). Our previous study showed that microwave cooking promoted lipid oxidation and formation of COPs (Hur et al., 2004). Oxi-

\footnotetext{
*Corresponding author: Seung Jae Lee, Department of Animal Science and Technology, Chung-Ang University, Anseong 456756, Korea. Tel: +82-31-670-4673; Fax: +82-31-675-3108; Email: seungjae99@daum.net
}

dized lipids including cholesterol not only affect food nutritional value, but have also been related to different adverse effects such as cytotoxicity, atherogenicity, mutagenicity, and carcinogenicity (Hur et al., 2013). Several studies have demonstrated the involvement of COPs in the rapid progression of coronary heart disease and atherosclerosis: COPs were shown to cause endothelial cell damage, which initiated complex series of pathological events that ultimately led to plaque formation $(\mathrm{Li}$ and Mehta, 2005; Poli et al., 2009; Sevanian et al., 1995). In most animals COPs are used as intermediate substances in the endogenous synthesis of several molecules such as bile acids and steroid hormones, and ingestion of the COPs-containing foods can increase their concentration in plasma (Vicente and Torres, 2007). Although many studies reported production of oxidized lipids including cholesterol in cooked meats, the influence of cooking methods on lipid digestibility and COPs formation during digestion remains to be elucidated. The purpose of this study was to investigate the effects of cooking methods on the digestibility of lipids and formation of COPs in 
pork patties during in vitro human digestion.

\section{Materials and Methods}

\section{Sample preparation}

Pork loins were ground twice through a $3 \mathrm{~mm}$-mincer plate, mixed with back fat (up to 20\%) for $5 \mathrm{~min}$ and used to make $100 \mathrm{~g}$ patties (approximately $9 \mathrm{~cm}$ in diameter, $1.5 \mathrm{~cm}$ thick). Patties were cooked by four different methods (oven cooking, pan frying, boiling, and microwaving) to an internal temperature of $85-90^{\circ} \mathrm{C}$.

1. Oven cooking: Patties were placed in a $2 \mathrm{~cm}$ deep pan and heated in convection oven set to $180^{\circ} \mathrm{C}$. Heat was generated by a heating bar and each patty was turned over twice in order to cook top and bottom surfaces. During cooking, samples were heated initially for $5 \mathrm{~min}$ on each side followed by a further $10 \mathrm{~min}$ per side. After heat treatment, patties were cooled to and held at $5^{\circ} \mathrm{C}$ or lower for $5 \mathrm{~min}$.

2. Pan frying: Patties were placed on an electric pan (30 cm diameter, $5 \mathrm{~cm}$ depth) and cooked at $180^{\circ} \mathrm{C}$ for a total of $5 \mathrm{~min}$ ( $2 \mathrm{~min} 30 \mathrm{~s}$ each side). To stabilize the temperature of the iron pan, it was preheated for $5 \mathrm{~min}$ before adding of the sample. After heat treatment, patties were cooled to and held at $5^{\circ} \mathrm{C}$ or lower for $5 \mathrm{~min}$.

3. Boiling: Patties were put into a zipper bag, then gently squeeze out the air and dipped into boiling water (water bath) for $5 \mathrm{~min}$. After heat treatment, patties were cooled to and held at $5^{\circ} \mathrm{C}$ or lower for $5 \mathrm{~min}$.

4. Microwaving: Patties were placed on a glass dish and cooked in a microwave oven $(3,000 \mathrm{MHz})$ with turning over twice between cycles. Core temperature was measured with a flexible internal thermometer (Temp 300, Thermo Scientific, USA). The cooked samples were vacuum packaged in an oxygen-proof PVDC bag and stored at $0-4^{\circ} \mathrm{C}$ until use.

\section{In vitro human digestion model}

We used a modified in vitro human digestion model described in previous studies (Hur et al., 2009; Versantvoort et al., 2005). The model imitated the following digestive stages:

I. Pre-Ingestion: pork patties.

II. Mouth: $5 \mathrm{~g}$ of pork patties were mixed with $6 \mathrm{~mL}$ of simulated saliva fluid (pH 6.8) and stirred for $5 \mathrm{~min}$ at $37^{\circ} \mathrm{C}$.

III. Stomach: $12 \mathrm{~mL}$ of simulated gastric fluid (pH 2) was added and the mixture was stirred for $2 \mathrm{~h}$ at $37^{\circ} \mathrm{C}$.

IV. Small Intestine: $12 \mathrm{~mL}$ of duodenal juice, $6 \mathrm{~mL}$ of bile juice, and $2 \mathrm{~mL}$ of sodium bicarbonate solution ( $\mathrm{pH}$ 6.5-7) were added, and the mixture was stirred for $2 \mathrm{~h}$ at $37^{\circ} \mathrm{C}$.

Composition of the simulated saliva, gastric, duodenal, and bile fluids are listed in Table 1. During the in vitro digestion, process samples were swirled at $60 \mathrm{rpm}$ in a shaking water bath (Model HB-205SW, Hanbaek, Co., Korea) to simulate gastrointestinal tract motility.

\section{Total lipid digestibility}

The digestibility of total lipids in the pork patties dur-

Table 1. Composition of various synthetic juices used in in vitro human digestion model

\begin{tabular}{|c|c|c|c|c|}
\hline & $\overline{\text { Saliva }}$ & Gastric juice & Duodenal juice & Bile juice \\
\hline \multirow{6}{*}{$\begin{array}{l}\text { Inorganic } \\
\text { components }\end{array}$} & $10 \mathrm{ml} \mathrm{KCl} 89.6 \mathrm{~g} / \mathrm{l}$ & $15.7 \mathrm{ml} \mathrm{NaCl} 175.3 \mathrm{~g} / \mathrm{l}$ & $40 \mathrm{ml} \mathrm{NaCl} 175.3 \mathrm{~g} / \mathrm{l}$ & $30 \mathrm{ml} \mathrm{NaCl} 175.3 \mathrm{~g} / \mathrm{l}$ \\
\hline & $10 \mathrm{ml} \mathrm{KSCN} 20 \mathrm{~g} / \mathrm{l}$ & $3.0 \mathrm{ml} \mathrm{NaH}{ }_{2} \mathrm{PO}_{4} 88.8 \mathrm{~g} / \mathrm{l}$ & $40 \mathrm{ml} \mathrm{NaHCO} 384.7 \mathrm{~g} / \mathrm{l}$ & $68.3 \mathrm{ml} \mathrm{NaHCO} 384.7 \mathrm{~g} / \mathrm{l}$ \\
\hline & $10 \mathrm{ml} \mathrm{NaH}{ }_{2} \mathrm{PO}_{4} 88.8 \mathrm{~g} / 1$ & $9.2 \mathrm{ml} \mathrm{KCl} 89.6 \mathrm{~g} / \mathrm{l}$ & $10 \mathrm{ml} \mathrm{KH_{2 }} \mathrm{PO}_{4} 8 \mathrm{~g} / \mathrm{l}$ & $4.2 \mathrm{ml} \mathrm{KCl} 89.6 \mathrm{~g} / \mathrm{l}$ \\
\hline & $10 \mathrm{ml} \mathrm{NaSO}_{4} 57 \mathrm{~g} / \mathrm{l}$ & $18 \mathrm{ml} \mathrm{CaCl} 2 \cdot 2 \mathrm{H}_{2} \mathrm{O} 22.2 \mathrm{~g} / 1$ & $6.3 \mathrm{ml} \mathrm{KCl} 89.6 \mathrm{~g} / \mathrm{l}$ & $150 \mu \mathrm{l} \mathrm{HCl} 37 \% \mathrm{~g} / \mathrm{g}$ \\
\hline & $1.7 \mathrm{ml} \mathrm{NaCl} 175.3 \mathrm{~g} / \mathrm{l}$ & $10 \mathrm{ml} \mathrm{NH}_{4} \mathrm{Cl} 30.6 \mathrm{~g} / \mathrm{l}$ & $10 \mathrm{ml} \mathrm{MgCl}{ }_{2} 5 \mathrm{~g} / 1$ & \\
\hline & $20 \mathrm{ml} \mathrm{NaHCO} 384.7 \mathrm{~g} / \mathrm{l}$ & $6.5 \mathrm{ml} \mathrm{HCl} 37 \% \mathrm{~g} / \mathrm{g}$ & $180 \mu \mathrm{l} \mathrm{HCl} 37 \% \mathrm{~g} / \mathrm{g}$ & \\
\hline \multirow[b]{2}{*}{$\begin{array}{l}\text { Organic } \\
\text { components }\end{array}$} & $8 \mathrm{ml}$ urea $25 \mathrm{~g} / \mathrm{l}$ & $10 \mathrm{ml}$ glucose $65 \mathrm{~g} / \mathrm{l}$ & $4 \mathrm{ml}$ urea $25 \mathrm{~g} / \mathrm{l}$ & $10 \mathrm{ml}$ urea $25 \mathrm{~g} / \mathrm{l}$ \\
\hline & & $\begin{array}{l}10 \mathrm{ml} \text { glucuronic acid } 2 \mathrm{~g} / 1 \\
3.4 \mathrm{ml} \text { urea } 25 \mathrm{~g} / \mathrm{l} \\
10 \mathrm{ml} \text { glucosamine } \\
\text { hydrochloride } 33 \mathrm{~g} / \mathrm{l}\end{array}$ & & \\
\hline \multirow{4}{*}{$\begin{array}{l}\text { Add to mixture } \\
\text { of organic }+ \\
\text { inorganic } \\
\text { components }\end{array}$} & $290 \mathrm{mg} \alpha$-amylase & $1 \mathrm{~g} \mathrm{BSA}$ & $9 \mathrm{ml} \mathrm{CaCl} \cdot 2 \mathrm{H}_{2} \mathrm{O} 22.2 \mathrm{~g} / \mathrm{l}$ & $10 \mathrm{ml} \mathrm{CaCl} \cdot 2 \mathrm{H}_{2} \mathrm{O} 22.2 \mathrm{~g} / \mathrm{l}$ \\
\hline & $15 \mathrm{mg}$ uric acid & $2.5 \mathrm{~g}$ pepsin & $1 \mathrm{~g} \mathrm{BSA}$ & $1.8 \mathrm{~g} \mathrm{BSA}$ \\
\hline & $25 \mathrm{mg}$ mucin & $3 \mathrm{~g}$ mucin & $9 \mathrm{~g}$ pancreatin & $30 \mathrm{~g}$ bile \\
\hline & & & $1.5 \mathrm{~g}$ lipase & \\
\hline $\mathrm{pH}$ & $6.8 \pm 0.2$ & $1.30 \pm 0.02$ & $8.1 \pm 0.2$ & $8.2 \pm 0.2$ \\
\hline
\end{tabular}

For all inorganic and organic solutions, distilled water was added up to $500 \mathrm{~mL}$. If necessary, $\mathrm{pH}$ of the juices was adjusted to the appropriate level. 
ing simulated human gastrointestinal digestion was determined by the rates of infiltration through dialysis tubing and expressed as percentage of total lipids inside and outside dialysis bags. Briefly, the dialysis tubing was purchased from Spectrum Laboratories Inc. (Rancho Dominguez, USA) with a molecular weight cut-off of 12-14 kDa. The dialysis tubing was cut into pieces of $10 \mathrm{~cm}$ and soaked in distilled water at $4^{\circ} \mathrm{C}$ before usage. After stomach digestion, the sample was then transferred to dialysis bags with duodenal juice, bile juice and sodium bicarbonate solution. The dialysis tubes with digestive samples were placed into a sodium phosphate buffer ( $\mathrm{pH}$ 6.9) and then incubated at $37^{\circ} \mathrm{C}$ for $2 \mathrm{~h}$ in a stirred water bath.

Digestibility $(\%)=($ lipid concentration inside the dialysis tube - lipid concentration outside the dialysis tube) / (lipid concentration inside the dialysis tube) $\times 100$

\section{Total lipid content}

Total lipids were extracted with chloroform and methanol as previously described (Folch et al., 1957). Each meat sample $(5 \mathrm{~g})$ was combined with $50 \mathrm{~mL}$ of Folch reagent (chloroform/methanol, 2:1 v/v) and $50 \mathrm{~mL}$ of $10 \%$ butylhydroxyanisole and homogenized using a Polytron homogenizer (IKA, Model T25, Germany) for $10 \mathrm{~s}$. The homogenate was filtered through Whatman No. 1 filter paper. The remaining sediment and filter paper were blended with $50 \mathrm{~mL}$ of Folch reagent and refiltered. Distilled water $(25 \mathrm{~mL})$ was added to the filtered extract and the mixture was centrifuged at $500 \mathrm{~g}$ for $10 \mathrm{~min}$. The upper layer of methanol and water was removed with an aspirator, and the bottom chloroform layer with extracted lipids was passed through anhydrous sodium sulfate $\left(\mathrm{Na}_{2}\right.$ $\mathrm{SO}_{4}$ ) which then was rinsed with $30 \mathrm{~mL}$ of chloroform. The extracts were concentrated at $40^{\circ} \mathrm{C}$ using an evaporator (Zymarkturbovap 500, USA).

\section{Free fatty acid content}

Free fatty acid content was determined by the modified AOAC method (AOAC, 1995) and quantified by titrimetry as the amount of $\mathrm{KOH}$ required to neutralize carboxylic acid in $1 \mathrm{~g}$ of sample. Pork patty samples $(5 \mathrm{~g})$ were homogenized in $50 \mathrm{~mL}$ test tubes with $15 \mathrm{~mL}$ of deionized distilled water at $1000 \mathrm{~g}$ for $10 \mathrm{~s}$ using a Polytron homogenizer. The homogenate $(2 \mathrm{~mL})$ was transferred to a $300 \mathrm{~mL}$ flask, and $100 \mathrm{~mL}$ of ether/ethanol mixture (1: $1, \mathrm{v} / \mathrm{v}$ ) was added. Several drops of phenolphthalein were added and free fatty acid content was determined by titration with $0.1 \mathrm{M} \mathrm{KOH}$ according to the equation: free fatty acids $(\mathrm{KOH} / \mathrm{g})=$

$5.611 \times \mathrm{A} \times \mathrm{F} /$ sample weight $(\mathrm{g})$

where $\mathrm{A}$ is the volume of $0.1 \mathrm{M} \mathrm{KOH}(\mathrm{mL})$ and $\mathrm{F}$ is the titer of $\mathrm{KOH}$.

\section{Thiobarbituric acid-reactive substances (TBARS)}

TBARS content was determined by the modified method described previously (Buege and Aust, 1978). Samples of pork patties $(5 \mathrm{~g})$ pre- and post-digestion were placed in $50 \mathrm{~mL}$ test tubes and homogenized with $15 \mathrm{~mL}$ of deionized distilled water using a Polytron homogenizer at $1000 \mathrm{~g}$ for $10 \mathrm{~s}$. One $\mathrm{mL}$ of pork patty homogenate was transferred to a disposable test tube $(3 \times 100 \mathrm{~mm})$, and 50 $\mu \mathrm{L}$ of $10 \%$ butylated hydroxyanisole and $2 \mathrm{~mL}$ thiobarbituric acid/trichloroacetic acid (TBA/TCA) were added. The mixture was vortexed and incubated in boiling water for $15 \mathrm{~min}$ to develop color. Samples were cooled in cold water for $5 \mathrm{~min}$, vortexed, and centrifuged for $15 \mathrm{~min}$ at $2000 \times g$. The absorbance of the resulting supernatant was determined at $531 \mathrm{~nm}$ against a blank containing $1 \mathrm{~mL}$ of deionized distilled water and $2 \mathrm{~mL}$ of TBA/TCA solution. TBARS were calculated based on a standard curve of malondialdehyde (MA), freshly prepared by acidification of 1,1,3,3-tetraethoxypropane in the range between 0.02 and $0.3 \mu \mathrm{g} / \mathrm{mL}(y=0.8729 x+0.0382, r=0.9961)$ and expressed as mg of MA per $\mathrm{kg}$ of sample.

\section{Cholesterol oxidation products}

COPs formation in samples was determined as previously described (Ahn et al., 1999). The dried lipid samples (Folch et al., 1957) were dissolved in hexane to concentration of $0.1 \mathrm{~g} \mathrm{fat} / \mathrm{mL}$ hexane. Silicic acid (100 mesh), celite-545, and $\mathrm{CaHPO}_{4}$ were mixed at 10:9:1 (w/w/w) in chloroform and packaged into a glass column. The columns were washed with $10 \mathrm{~mL}$ of hexane/ethyl acetate $(9: 1, \mathrm{v} / \mathrm{v})$ and $0.2 \mathrm{~g}$ of lipid samples in hexane was added with an internal standard ( $5 \alpha$-cholestane) and loaded onto the silicic acid column. Neutral lipids, phospholipids, and cholesterol were eluted by hexane/ethyl acetate $(9: 1, \mathrm{v} / \mathrm{v})$ and hexane/ethyl acetate/diethyl ether (4:1:2, v/v/v). COPs were eluted with acetone/ethyl acetate/methanol (10:10:1) and dried under nitrogen. The dried COPs were mixed with $200 \mu \mathrm{L}$ pyridine and $100 \mu \mathrm{L}$ bis-[trimethylsilyl]trifluoroacetamide $+1 \%$ trimethylchlorosilane, derivatized by heating at $80^{\circ} \mathrm{C}$ for $1 \mathrm{~h}$ in a dry bath, and analyzed using a gas chromatograph (Agilent 6890, USA) equipped with an on-column capillary injector and a flame ionization detector. A ramped oven temperature conditions 
$\left(180^{\circ} \mathrm{C}\right.$ for $2.5 \mathrm{~min}$, increased to $230^{\circ} \mathrm{C}$ at $2.5^{\circ} \mathrm{C} / \mathrm{min}$, then held at $230^{\circ} \mathrm{C}$ for $7.5 \mathrm{~min}$ ) were used. Temperature of both the inlet and detector was $280^{\circ} \mathrm{C}$. Helium was the carrier gas with linear flow at $1.1 \mathrm{~mL} / \mathrm{min}$. Detector air, $\mathrm{H}_{2}$, and make-up gas (He) flows were 350, 35, and 43 $\mathrm{mL} / \mathrm{min}$, respectively. Six COPs were analyzed ( $7 \alpha$-hydroxycholesterol, 7 $\beta$-hydroxycholesterol, 7-ketocholesterol, $20 \alpha$-hydroxycholesterol, cholestanetriol, and 25-hydroxycholesterol) to assess total COPs amount. COPs were identified by comparison of retention times with those of known standards. Relative quantities were expressed as percent $(w / w)$ of total COPs.

\section{Statistical analysis}

Statistical analyses were conducted for three batches of pork patties. Analyses of variance (ANOVA) were performed to test the effects of cooking methods on pork digestibility, free fatty acids content, lipid oxidation, and COPs formation using SAS software (SAS Inst. Inc., USA). Data were expressed as the mean $(n=15)$ with standard deviation (SD) and differences between samples were considered significant at $p<0.05$.

\section{Results}

Effects of cooking methods on the digestibility of total lipids are shown in Fig. 1. In in vitro human digestion model, total lipid digestibility was significantly higher in the microwave-cooked samples, whereas the pan-fried patties showed significantly lower total lipid digestibility compared with those cooked by the other methods.

Effects of cooking methods on free fatty acid content are shown in Fig. 2. All cooking methods resulted in increased levels of free fatty acids in the digested sam-

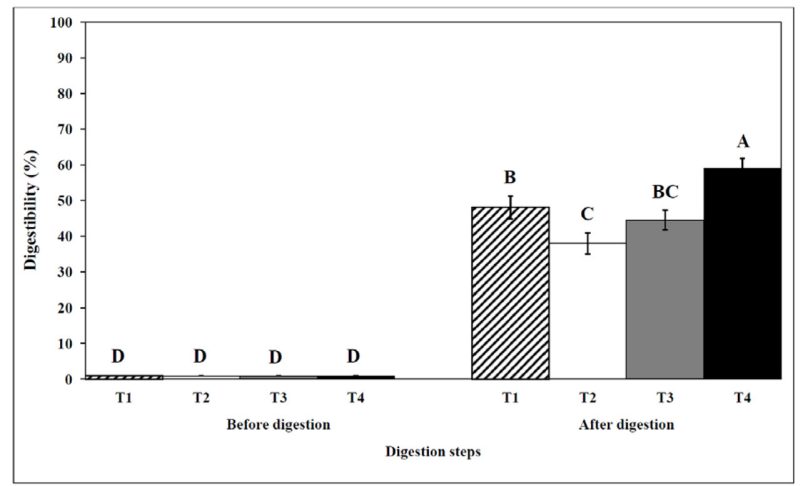

Fig. 1. Effect of cooking methods on total lipid digestibility in pork patties subjected to in vitro human digestion. Cooking methods: oven (T1), pan-frying (T2), boiling (T3), microwave heating (T4).

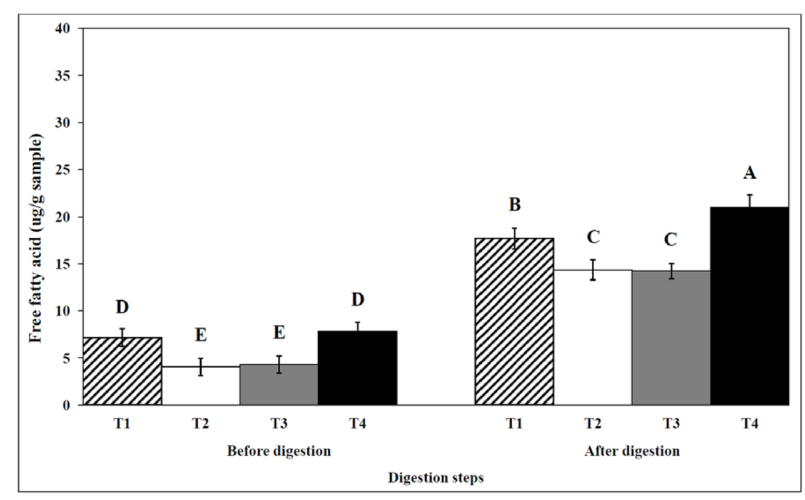

Fig. 2. Effect of cooking methods on the free fatty acid contents in pork patties subjected to in vitro human digestion. Cooking methods: oven (T1), pan-frying (T2), boiling (T3), microwave heating (T4).

ples. However, patties cooked in the microwave showed significantly higher free fatty acid content after in vitro digestion than those cooked by frying or boiling. The release of free fatty acids indicates that lipids including cholesterol were processed by digestive enzymes and bile salts during in vitro digestion. In this regard, higher free fatty acid content in the in vitro digested patties reflected increases in total lipid digestibility.

Effects of cooking methods on TBARS levels are shown in Fig. 3. TBARS formation is an indicator of lipid peroxidation and it was increased after in vitro human digestion in all cooked samples. Similar to free fatty acid levels, TBARS values were significantly higher in the patties subjected to in vitro digestion after microwaving and oven cooking, whereas pan-fried and boiled samples had lower TBARS levels.

Effects of cooking methods on cholesterol content are shown in Fig. 4. In all the samples cholesterol levels decreased significantly after in vitro digestion, possibly

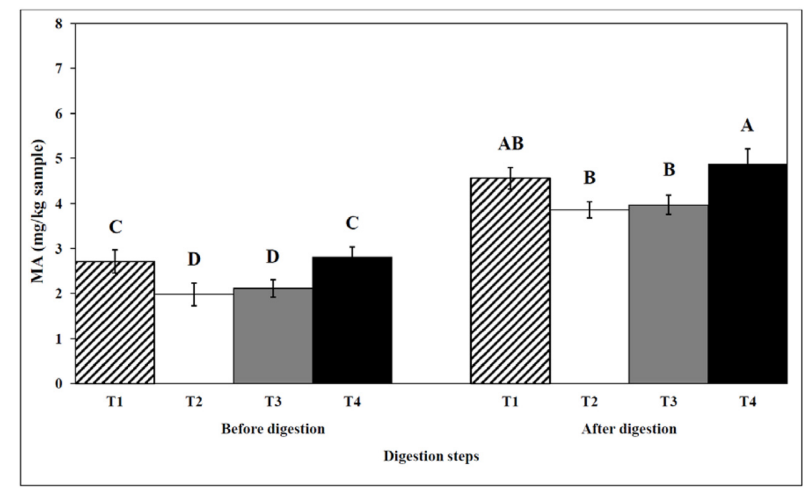

Fig. 3. Effect of cooking methods on TBARS concentration in pork patties subjected to in vitro human digestion. Cooking methods: oven (T1), pan-frying (T2), boiling (T3), microwave heating (T4). 


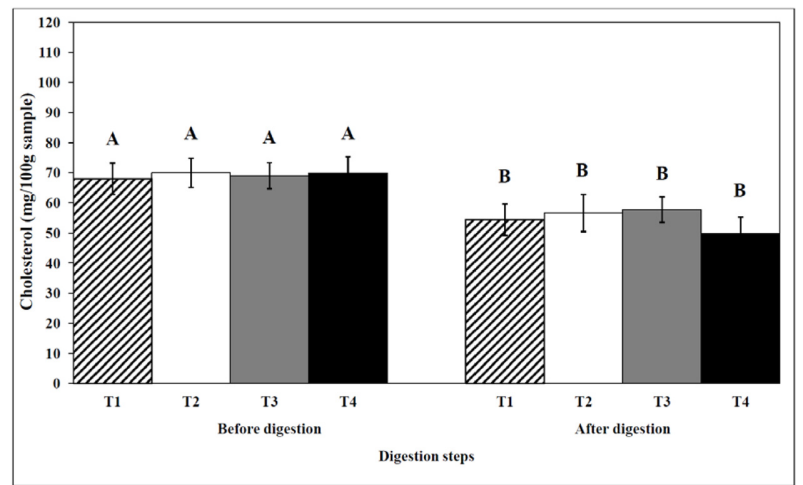

Fig. 4. Effect of cooking methods on the cholesterol contents in pork patties subjected to in vitro human digestion. Cooking methods: oven (T1), pan-frying (T2), boiling (T3), microwave heating (T4).

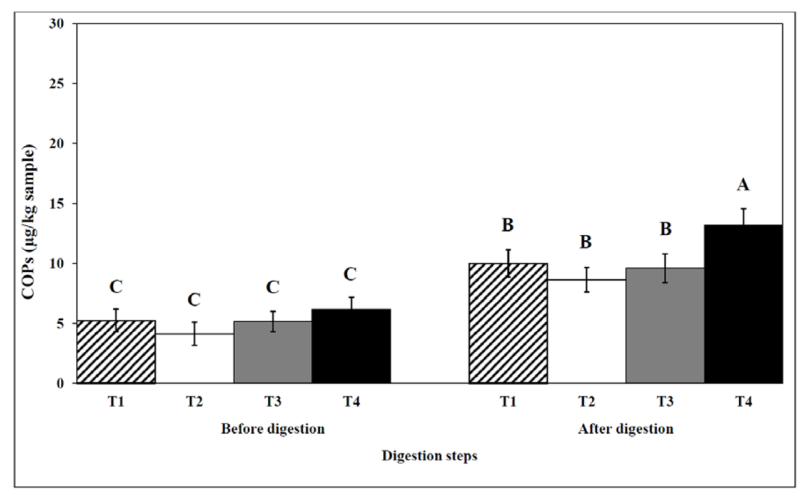

Fig. 5. Effect of cooking methods on COP concentration in pork patties subjected to in vitro human digestion. Cooking methods: oven (T1), pan-frying (T2), boiling (T3), microwave heating (T4).

owing to cholesterol's oxidization to COPs. However, cholesterol content in both undigested and digested patties was not significantly affected by cooking methods.

Effects of cooking methods on the total production of COPs are shown in Fig. 5. Before human digestion, the amount of total COPs did not vary significantly among the differently cooked samples although the levels of individual cholesterol oxides showed some changes depending on the cooking method. However, after in vitro digestion, the amount of total COPs was significantly higher in the microwave-cooked patties than in the other samples.

\section{Discussion}

Our results show that total lipid digestibility, lipid oxidation, cholesterol levels, and COPs production in samples subjected to human digestion in vitro were influ- enced by cooking methods. Total lipid digestibility, free fatty acid levels, lipid oxidation, and COPs formation were the highest in the samples cooked in microwave, followed by oven cooking, boiling, and pan-frying. It is well known that lipid oxidation occurs because of high temperature treatment during cooking and the degree of oxidation depends on cooking methods, processing temperature and time. We hypothesized that cooking methods influence total lipid digestibility and that the increased lipid oxidation is probably related to the damage of the cell membrane caused by heating. Several studies (Hernández et al., 1999; Rodriguez-Estrada et al., 1997) have shown that roasting, which is based on high temperature treatment during a long time, is characterized by increased lipid oxidation compared to other methods. It has been reported that cooking in microwave caused high lipid oxidation because the process promoted oxidative reactions (Rodrigeuz-Estrada et al., 1997). In this study, the microwave heating also resulted in higher levels of lipid oxidation (measured by TBARS production) and COPs generation and increased free fatty acid release compared to the other cooking methods, probably because the meat is more evenly heated than generally occurs in other cooking techniques. In contrast, during pan frying the heat is gradually conducted from the meat surface to the core, which is less efficient than heating in the microwave. This difference in thermal conduction may be the main reason why in vitro digestion resulted in higher total lipid digestibility and COPs contents for the microwave-treated patties than for the pan-fried samples. COPs formation in the cooked pork patties is promoted by high temperature treatments (Broncano et al., 2009; Conchillo et al., 2003; Grau et al., 2001). Several studies (Broncano et al., 2009; Chan et al., 1993) reported that heating of cholesterol-containing food increases COPs production. In this study, microwave treatment increased temperature in the pork patties more rapidly compared to the other cooking methods (data are not shown). The microwaving resulted in the highest levels of lipid digestibility and total COPs in the pork patties after in vitro digestion compared to the other cooking methods. In general, microwavebased heating is an extremely rapid method to cook meats. Heating is generated by electromagnetic radiation causing polarized molecules in the food to rotate and build up thermal energy by intermolecular interactions, therefore, the microwave method should more easily damage the cholesterol structure than other cooking methods.

Our results demonstrate that the rate of cholesterol oxidation in pork patties is considerably accelerated after 
human digestion in vitro, and appears to follow the same trend as lipid oxidation. These results are consistent with previous findings showing positive correlation between COPs and TBARS production (Broncano et al., 2009). In an early work of Smith et al. (1987), it was postulated that the hydroperoxides of polyunsaturated fatty acid formed during lipid oxidation may promote cholesterol oxidation. Unsaturated fatty acids with one or more double bonds between carbon atoms are chemically unstable and prone to oxidation (Hur et al., 2007), including that by diatomic molecular oxygen. The hydroperoxides of unsaturated fatty acid initiate oxidation of cholesterol. It has been reported (Chan et al., 1993) that lipid radicals formed during food processing and storage can accelerate the formation of COPs. Therefore, COPs production should correlate with lipid peroxidation and generation of free radicals from unsaturated fatty acids. Prevention of lipid oxidation during cooking may therefore result in decrease of cholesterol oxidation and COPs formation.

In the stomach, lipids and cholesterol are exposed to highly acidic environment ( $\mathrm{pH}$ 1-3) and subjected to enzymatic hydrolysis by gastric lipases. In the small intestine, partially hydrolyzed cholesterol is exposed to digestive juices containing cholesterol esterase; mixing of the chyme with alkali digestive juices containing bile salts and sodium bicarbonate causes elevation of $\mathrm{pH}$ levels to neutral which contributes to cholesterol oxidation (Hur et al., 2013). In our study, lipid oxidation and the release of free fatty acids indicate that lipids are hydrolyzed by digestive enzymes and bile salts during in vitro human digestion. Owing to the presence of a double bond, cholesterol is also susceptible to oxidation when exposed to digestive enzymes and bile salts. Moreover, the activity of dietary antioxidant enzymes can be decreased during digestion and protein denaturation contributing to lipid and cholesterol oxidation. This study showed that the production of COPs could be increased during digestion, and is promoted by easy and quick cooking methods such as microwave heating, which induces lipid and cholesterol oxidation. Consequently, lipid digestibility correlated with increases in lipid peroxidation and COPs formation. $\mathrm{Nu}-$ merous studies have suggested that the formation of COPs and lipid oxidation in meat can be minimized by the application of low processing temperatures, that is through minimal processing, by the use of oxygen-proof packaging and a protective atmosphere as well as by low temperature and high free storage, by the dietary antioxidants to animals or antioxidants addition to meats (Hur et al., 2007). A number of studies demonstrated that increased consumption of oxidized fat is directly related to atherosclerosis and coronary disease. Therefore, there is clearly an urgent need for more research aimed at development of safer cooking methods, which would reduce consumption of injurious oxidized lipids and COPs.

\section{Acknowledgments}

This research was supported by Basic Science Research Program through the National Research Foundation of Korea (NRF) funded by the Ministry of Science, ICT and Future Planning (NRF-2012R1A1A1010007).

\section{References}

1. Ahn, D., Lee, J., Jo, C., and Sell, J. (1999) Analysis of cholesterol oxides in egg yolk and turkey meat. Poultry Sci. 78, 1060-1064.

2. AOAC (1995) Official methods of analysis. Association of Office Analytical Chemists, Washington, DC.

3. Broncano, J. M., Petron, M. J., Parra, V., and Timon, M. L. (2009) Effect of different cooking methods on lipid oxidation and formation of free cholesterol oxidation products (COPs) in latissimus dorsi muscle of iberian pigs. Meat Sci. 83, 431437.

4. Buege, J. A. and Aust, S. D. (1978) Microsomal lipid peroxidation. Methods Enzymol. 52, 30-310.

5. Chan, S., Gray, J. I., Gomaa, E. A., Harte, B. R., Kelly, P. M., and Buckley, D. J. (1993) Cholesterol oxidation in whole milk powders as influenced by processing and packaging. Food Chem. 47, 321-328.

6. Conchillo, A., Ansorena, D., and Astiasarán, I. (2003) Combined effect of cooking (grilling and roasting) and chilling storage (with and without air) on lipid and cholesterol oxidation in chicken breast. J. Food Prot. 66, 840-846.

7. Folch, J., Lees, M., and Stanley, G. H. S. (1957) A simple method for the isolation and purification of total lipids from animal tissues. J. Biol. Chem. 226, 497-509.

8. Grau, A., Codony, R., Grimpa, S., Baucells, M. D., and Guardiola, F. (2001) Cholesterol oxidation in frozen dark chicken meat: Influence of dietary fat source, and a-tocopherol and ascorbic acid supplementation. Meat Sci. 57, 197-208.

9. Hernández, P., Navarro, J. L., and Toldrá, F. (1999) Lipids of pork meat as affected by various cooking techniques. Food Sci. Technol. Int. 5, 501-508.

10. Hur, S. J., Decker, E. A., and McClements, D. J. (2009) Influence of initial emulsifier type on microstructural changes occurring in emulsified lipids during in vitro digestion. Food Chem. 114, 253-262.

11. Hur, S. J., Joo, S. T., Park, G. B., Kim, I. S., and Jin, S. K. (2004) Effect of cooking and packaging methods on the thiobarbituric acid reactive substances and cholesterol oxidation products. J. Ani. Sci. Technol. 46, 397-404.

12. Hur, S. J., Min, B., Nam, K. C., Lee, E. J., and Ahn, D. U. 
(2013) Effect of dietary cholesterol and cholesterol oxides on blood cholesterol, lipids, and the development of atherosclerosis in rabbits. Int. J. Mol. Sci. 14, 12593-12606.

13. Hur, S. J., Park, G. B., and Joo, S. T. (2007) Formation of cholesterol oxidation products (COPs) in animal products. Food Control 18, 939-947.

14. Kesava Rao, V., Kowale, B. N., Babu, N. P., and Bisht, G. S. (1996) Effect of cooking and storage on lipid oxidation and development of cholesterol oxidation products in water buffalo meat. Meat Sci. 179-185.

15. Li, D. and Mehta, J. L. (2005) Oxidized ldl, a critical factor in atherogenesis. Cardiovasc. Res. 68, 353-354.

16. Poli, G., Sottero, B., Gargiulo, S., and Leonarduzzi, G. (2009) Cholesterol oxidation products in the vascular remodeling due to atherosclerosis. Mol. Aspects. Med. 30, 180-189.

17. Rodriguez-Estrada, M. T., Penazzi, G., Caboni, M. F., Bertacco, G., and Lercker, G. (1997) Effect of different cooking methods on some lipid and protein components of hamburg- ers. Meat Sci. 45, 365-375.

18. Sevanian, A., Hodis, H. N., Hwang, J., McLeod, L. L., and Peterson, H. (1995) Characterization of endothelial cell injury by cholesterol oxidation products found in oxidized ldl. $J$. Lipid Res. 36, 1971-1986.

19. Smith, L. L. (1987) Cholesterol autoxidation 1981-1986. Chem. Phys. Lipids 44, 87-125.

20. Versantvoort, C. H. M., Oomen, A. G., Van de Kamp, E., Rompelberg, C. J. M., and Sips, A. J. A. M. (2005) Applicability of an in vitro digestion model in assessing the bioaccessibility of mycotoxins from food. Food Chem. Toxicol. 43, 31-40.

21. Vicente, S. J. V. and Torres, E. A. F. S. (2007) Formation of four cholesterol oxidation products and loss of free lipids, cholesterol and water in beef hamburgers as a function of thermal processing. Food Control 18, 63-68.

(Received 2013.11.18/Revised 2014.3.11/Accepted 2014.4.7) 